\title{
Flower Ontogenesis and Fruit Development of Synsepalum dulcificum
}

\author{
Chen Xingwei and Thohirah Lee Abdullah ${ }^{1}$ \\ Floriculture lab, Crop Science Department, Faculty of Agriculture, \\ Universiti Putra Malaysia, 43400 Serdang, Selangore, Malaysia
}

\author{
Sima Taheri \\ Crop Science Department, Faculty of Agriculture, Universiti Putra \\ Malaysia, 43400 Serdang, Selangore, Malaysia
}

\begin{abstract}
Nur Ashikin Psyquay Abdullah
Department of Crop Science, Faculty of Agriculture and Food Science, Universiti Putra Malaysia Bintulu Campus, Jalan Nyabau, 97008 Bintulu, Sarawak, Malaysia
\end{abstract}

\section{Siti Aishah Hassan \\ Crop Science Department, Faculty of Agriculture, Universiti Putra Malaysia, 43400 Serdang, Selangore, Malaysia}

Additional index words. Synsepalum dulcificum, miracle fruit, ontogenesis, flower morphology

\begin{abstract}
Synsepalum dulcificum from the family Sapotaceae is known as miracle fruit and is a valuable horticultural species. All plant parts are of medicinal importance whereas the fruit known as magic berry, miracle berry, or sweet berry is consumed fresh. Surprisingly, very little is known on the species in terms of flower morphology and flower development. In this study, an observation on the flower morphology and flower development of miracle fruit has been made with the aid of microscopic techniques. Miracle fruit flower requires $\mathbf{1 0 0}$ days to develop from reproductive meristem to full anthesis. The flower development can be divided into six stages based on the size and appearance of the flower bud. The fruit with persistent style developed and ripened 90 days after anthesis. Heavy fruit drop was observed at 40-60 days after anthesis which contributed to the final fruit set of average of $\mathbf{5 . 0 6 \%}$ per plant. Through this study, miracle fruit is strongly insect pollinated and prevents self-fertilization. A study on pollination ecology is needed to identify the pollinator for miracle fruit, as this is important in manipulating fruit loading in the future.
\end{abstract}

Miracle berry ( $S$. dulcificum), also called miracle fruit or red berry, is an indigenous tropical plant growing in West Africa. It is a very promising species but a poorly studied resource. $S$. dulcificum is an evergreen shrub reaching $4 \mathrm{~m}$ tall. Leaves are entire, alternate, symmetrical, and obovate-lanceolate to broadly lanceolate and pointed at apex with $4.3-7.5 \mathrm{~cm}$ long and $3.1-3.8 \mathrm{~cm}$ wide. Flowers are bisexual, white, small, solitary, or in small clusters. The calyx consists of four to five sepals, the corolla with four to five petals, and the androecium with five stamens. Within the gynoecium, the style is simple, erect with an inconspicuous stigma. The ovary is superior with the outer wall heavily covered with hairs. Fruit is an ovoid to oblong berry $2-2.5 \mathrm{~cm}$ long, $1 \mathrm{~cm}$ wide, finely pubescent, with a persistent protruding style, green turning to bright red when ripe. It has a large seed surrounded by a thin layer of berry flesh with a faint cherrylike flavor (Achigan-Dako et al., 2015; Chen et al., 2012; Du et al., 2014).

Received for publication 23 Dec. 2015. Accepted for publication 4 Apr. 2016.

${ }^{1}$ Corresponding author. E-mail: thohirah@upm. edu.my.
Miracle fruit is a rare fruit crop with high economical value in the medical and food industry.

The fleshy pulp of the miracle fruit contains miraculin, which is a glycoprotein with tastemodifying activity. Miraculin exerts an extraordinary effect on the taste buds of the tongue where it makes every sour or acidic food eaten or drunk to taste sweet (Kant, 2005; Temussi, 2006). Miraculin could possibly help diabetics to eat sweet food without taking in sugar and has been investigated as a possible source for a natural food sweetener (Kant, 2005).

Scientific literature on the type of pollination for $S$. dulcificum is scarce. However, flowers are hermaphrodite and the species is certainly autogamous. Crosspollination is also possible as well. Knowledge on floral biology and pollination is of paramount importance for breeding; and for $S$. dulcificum more data are needed. $S$. dulcificum is an evergreen species which flowers and fruits throughout the year. However, the phenological phases (e.g., growth duration, flowering time, fruiting time, and maturation time) need further investigation to complete previous investigation by Oumorou et al. (2010) who reported that flowering and fruiting occur two to three times per year.
According to that report, in Benin, the species flowers from April to May, July to August, and from November to December and fruits are available in May, August, October, and from December to February (Oumorou et al., 2010). When there is no disturbance (e.g., wind, birds, and overexploitation by human), stands bear mature fruit for 30-60 d.

The study of the flower initiation and development of high economical value crop provide further informative insights of the mechanisms in manipulating flowering process and fruit loading (Teeri et al., 2006; Tromp, 2000; Valiente and Albrigo, 2004). Such study has economical and scientific importance especially in botany and agricultural investigations (Dennis et al., 2006; Esumi et al., 2007; Teeri et al., 2006). Floral initiation is an important process in plant development where the plant undergoes physiological and structural changes from the vegetative stage to reproductive stage involving the changes in the apex geometry and inception of the flower primordial (Albrechtova et al., 2004; Jaeger et al., 2006; Kwiatkowska, 2006). With the aid of microscopic techniques, the transition of vegetative primordial to reproductive stage can be detected (Foster et al., 2003; Kurokura et al., 2005; Kwiatkowska, 2006) and scanning electron microscope (SEM) has been used for observation at higher definition in the floral structure and development of fruit crops (Esumi et al., 2007; Foster et al., 2003).

Despite the importance of miracle fruit in the horticultural and food industry, many studies had been conducted focusing on the miraculin (Kant, 2005; Temussi, 2006). The study on flower morphology of miracle fruit which been done by Ayensu (1972) and the existence of petaloid staminodes had been reported. However, the study of the flower ontogeny and development of miracle fruit is still lacking. In this study, an observation on the flower morphology and flower development of miracle fruit has been conducted with the aid of microscopic techniques and description of flower and fruit developmental stages. Our results could improve understanding of pollination ecology and methods to manipulate flowering and fruit development.

\section{Materials and Methods}

Experimental location and plant material. This study was conducted at field site no. 2, Universiti Putra Malaysia. Four-year-old flowering miracle fruit plants were maintained under a rain shelter with controlled irrigation. Plants were irrigated for $30 \mathrm{~min}$ at 7:00 $\mathrm{AM}$ and 4:00 PM daily. Complex fertilizer NPK Blue (12:12:17+ $2 \mathrm{Mg}+\mathrm{TE})$ included nitrogen $(12 \%)$, phosphorous $(5.2 \%)$, potassium $(14.1 \%)$, magnesium $(1.2 \%)$, and trace elements (TE) such as iron, zinc, boron, copper, and manganese were applied monthly at $5 \mathrm{~g}$ per plant.

Methodology for flower ontogenesis. Shoots of miracle fruit were tagged and collected from 10 plants. The flowers in different developmental stages (Fig. 3) were collected randomly and observed under light 
microscope. Six developmental stages of $S$. dulcificum flowers were categorized according to size and the appearance of the flower bud: Stage I, calyx formation (4-30 d); Stage II, peduncle elongation and flower bud enlargement (31-65 d); Stage III, calyx color change from yellow-green to brown (66-85 d); Stage IV, elongation of petals, style and stamens (86-99 d); Stage V, anthesis (100-101 d); and Stage VI, senescence $(102-103 \mathrm{~d})$. The inflorescence size was determined by measuring 20 samples from each stage. Flowers and flower buds were dissected under a microscope and further processed for observation using SEM following standard procedure described by Kassel and Shih (2012).

Specimens were fixed in formalin-acetic acid-alcohol (FAA, formalin: acetic acid: $70 \%$ alcohol at 1:1:18) for $3 \mathrm{~d}$ before being further processed. Method for preparing $100 \mathrm{~mL}$ FAA included $5 \mathrm{~mL}$ of formalin $40 \%, 5 \mathrm{~mL}$ of acetic acid glacial, and $90 \mathrm{~mL}$ of ethanol $70 \%$.

Specimens were then placed in a highpressure $(630 \mathrm{~mm} \mathrm{Hg}$ ) vacuum oven for $2 \mathrm{~h}$ to remove the air bubble in the specimens and were placed overnight in $1 \%$ osmium tetroxide. The next day, water contained in the cells and tissues was removed by soaking the specimens for $30 \mathrm{~min}$ in a series of ethanol with different concentrations ranging from $30 \%, 50 \%, 70 \%, 85 \%$, and $95 \%$ and soaked twice in $100 \%$ absolute ethanol for $60 \mathrm{~min}$.

Specimens with absolute alcohol were transferred to critical point dryer [CPD 030, Leica (Balzers), Singapore]. The chamber was cooled down to $10^{\circ} \mathrm{C}$. Liquefied carbon dioxide $\left(\mathrm{CO}_{2}\right)$ as drying agent was channeled into the chamber slowly for $2-3 \mathrm{~min}$ and the specimens were exposed to $\mathrm{CO}_{2}$ for $5 \mathrm{~min}$. Part of the liquefied $\mathrm{CO}_{2}$ was drained out and a fresh flow of $\mathrm{CO}_{2}$ was then provided for 1-2 min so the specimens were exposed to $\mathrm{CO}_{2}$ for $5 \mathrm{~min}$. This process was repeated for three times before filling up the drying agent to just below upper edge of front sight glass. The cooling process was stopped and the specimen chamber was heated up to $38-40{ }^{\circ} \mathrm{C}$. The pressure within the specimen chamber was raised to about 86-100 psi during the heating process. When the liquid medium changed to gaseous phase, the exit valve was slowly opened to allow the $\mathrm{CO}_{2}$ gas escape from the specimen chamber under slowed controlled rate. The chamber was depressurized over a period of $10 \mathrm{~min}$ to prevent decompression damage to the specimen. Dried samples were mounted on metal stubs with sticky double sided tape. The specimens were sputter-coated with 10-30 nm layer of goldpalladium and were observed under SEM (JSM-5610LV; JEOL USA, Inc., MA) and micrographs were obtained as well.

Methodology for fruit development. From each 10 tagged plants, five flowering branches were observed for fruit development and total fruit set. Percentage of successful developed fruits was obtained by dividing the total number of fruits with the total number of observed flowers. The fruits in different stages of development were collected randomly and
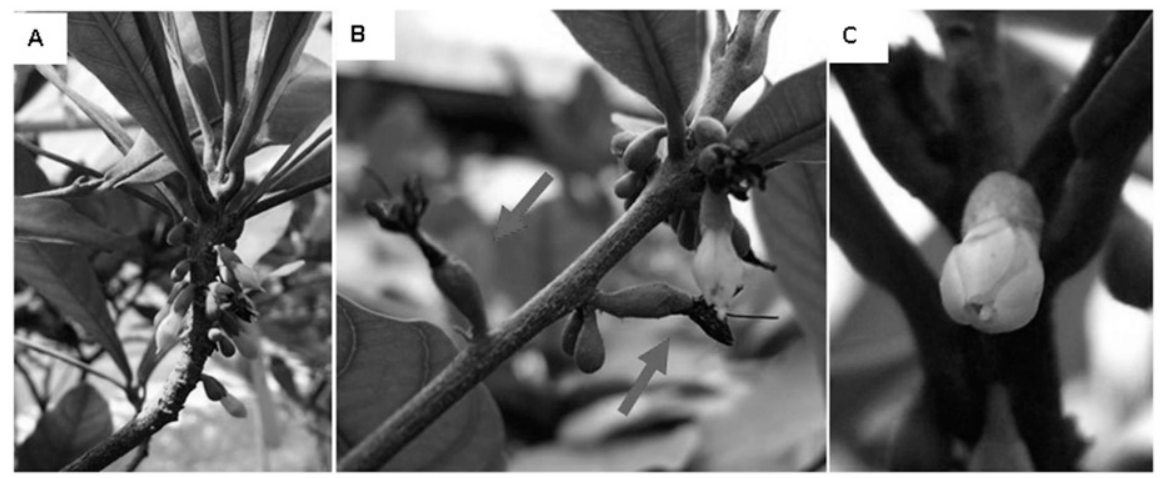

Fig. 1. Flower of Synsepalum dulcificum. (A) Subsessile solitary flowers emerging in single between the leaf axil and stem. (B) Various flower and fruit developmental stages (arrowed) can be found at the same time in a plant. (C) Flower partially opens during anthesis.
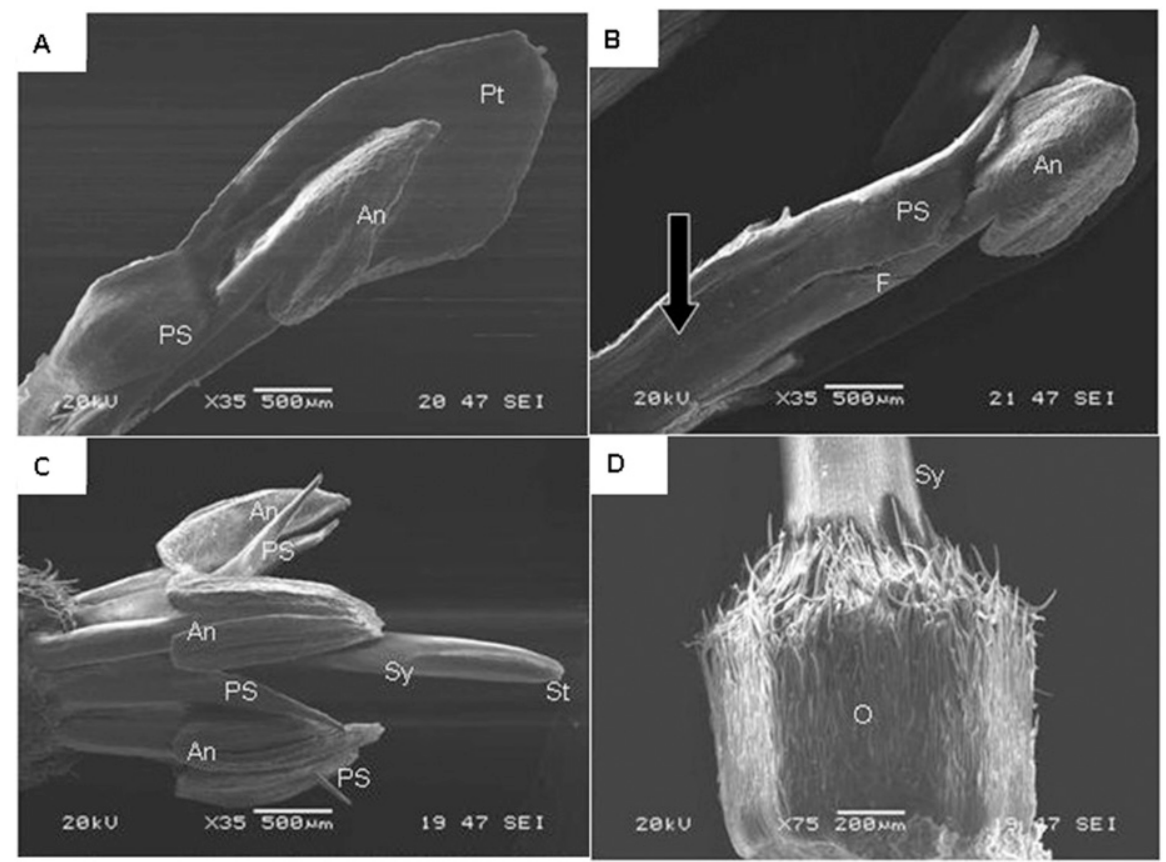

Fig. 2. Micrographs showing flower parts of Synsepalum dulcificum. (A) Petaloid staminode (PS) accompanying each stamen with cordiform anther (An) situated next to a petal (pt). Scale bar = $500 \mu \mathrm{m}$. (B) The stamens and PS fused at the base (arrowed). Scale bar $=500 \mu \mathrm{m}$. (C) Style (Sy) with undifferentiated stigma (St) is longer than stamen. Scale bar $=500 \mu \mathrm{m}$. (D) Ovary $(\mathrm{O})$ superior covered with densely pack tapering trichomes. Scale bar $=200 \mu \mathrm{m}$.

observed under microscope. The fruit size in different developing stages was determined by measuring 20 samples from each stage.

\section{Results and Discussion}

Flower ontogenesis of miracle fruit. Miracle fruit produced tubular flowers. The solitary flowers were produced in single, in pairs, or in a cluster of four to eight flowers at the leaf axils and axillary buds on the stem. The flower was developed at the leaf axil of new shoot or at the old axillary floral bud which had produced earlier flowers. The cauliflorous and pendulous flower was subsessile and bloomed throughout the year (Fig. 1A). Various flower and fruit developmental stages could be found at the same time in a plant (Fig. 1B) showing that flowering is nonsimultaneous. The hermaphroditic flower

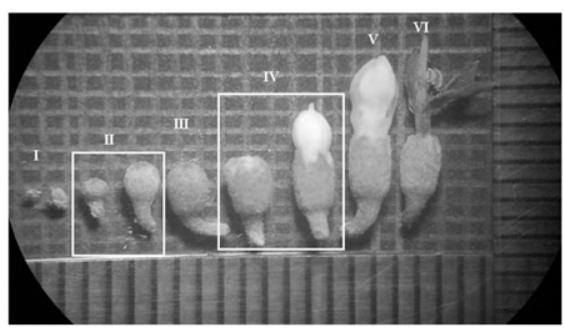

Fig. 3. Six developmental stages of Synsepalum dulcificum flowers categorized according to size: Stage I, calyx formation (4-30 d); Stage II, peduncle elongation and flower bud enlargement (31-65 d); Stage III, calyx color change from yellow-green to brown (66-85 d); Stage IV, elongation of petals, style and stamens (86-99 d); Stage V, anthesis (100$101 \mathrm{~d})$; Stage VI, senescence (102-103 d). Scale bar $=1 \mathrm{~mm}$ 
was partially open during anthesis (Fig. 1C) and was highly scented with coco butter like fragrance. The calyx was ribbed and the outer epidermis was covered with trimbriate trichomes.

The corolla contained five petals arranged in convolute forming a narrow corolla tube by the basal coalescence with five petaloid staminodes or petaloid appendages; each stamen consisted of five cordiform anthers and a filament encircling the gynoecium at the base with the corolla. Each of the five epipetalous stamens was located opposite of a petal (Fig. 2A). The petaloid staminodes had the same color with the corolla which was creamish white but differed from the petals in size and shape. The petaloid staminodes developed adjacent to each fertile stamen and were in between the stamen and pistil (Fig. 2A) with shorter length than the stamen. The stamens and petaloid staminodes were fused at the base (Fig. 2B). The elongated simple erect style enabled the undifferentiated stigma to protrude above the anthers (Fig. 2C). The anthers dehisced extrorsely by longitudinal slits and dispersed the fine pollen grains measuring around 16$17 \mu \mathrm{m}$. The ovary was superior with the outer wall heavily covered with tapering trichomes (Fig. 2D).

The flower development sequences were divided into six stages based on the size and appearance of the flower bud (Fig. 3). Stage I, calyx formation (4-30 d): young flower bud less than $1 \mathrm{~mm}$ developed under a hairy bracts; Stage II, peduncle elongation and flower bud enlargement (31-65 d): peduncle elongated to $2 \mathrm{~mm}$ and flower bud grew above the bracts. The yellow-green flower bud increased in size from 1 to $2 \mathrm{~mm}$ wide and $3 \mathrm{~mm}$ in length; Stage III, calyx color changed from yellow-green to brown (66$85 \mathrm{~d})$ : brown flower bud measuring around 3-4 mm in length; and Stage IV, elongation of petals, style and stamens (86-99 d): creamy white petals became visible and style with inconspicuous stigma extended above the petals. The flower size remained at $2 \mathrm{~mm}$ wide and reached to $8-9 \mathrm{~mm}$ in length. Stage $\mathrm{V}$, anthesis (100-101 d): flower partially opened in the evenings, highly scented with coco butter like fragrance; and Stage VI, senescence $(102-103 \mathrm{~d})$ : petals, stamen and petaloid staminodes turned brown while the style remained fresh.

The flower bud developed at the axillary bud at the leaf axil. The reproductive meristem or flower primordium was differentiated from the vegetative apical meristem or leaf primordium through the appearance and shape. The apex of flower primordium was flat and broad while the apex of leaf primordium was tapering and narrower (Fig. 4A). The dome shape flower primordial was surrounded by a pair of hairy bracts which appeared before the sepals (Fig. 4B). During the early ontogenetic stage (Stage I), a pair of hairy sepals developed laterally (Fig. 4C), followed by another pair of sepals and formed a total of four sepals arching inwards (Fig. 4D). The initiation of petals
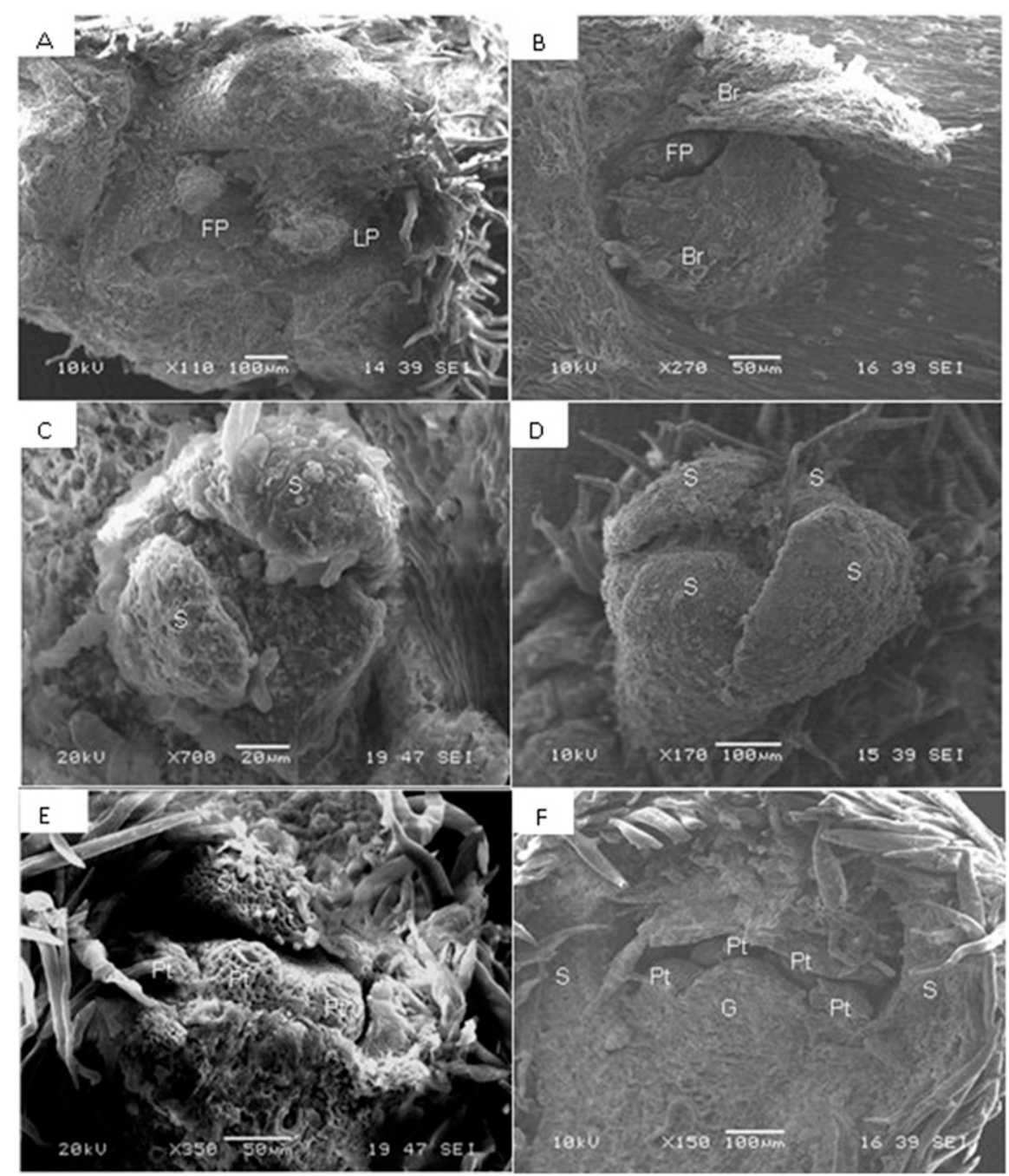

Fig. 4. Micrographs showing flower initiation and early floral development of Synsepalum dulcificum. (A) Leaves and bracts of a newly developed shoot had been removed, showing the flat and broad reproductive apical meristem or a flower primordium (FP) developed from leaf axil and compared with a narrow and tapering vegetative apical meristem or leaf primordium (LP). Scale bar $=100 \mu \mathrm{m}$. (B) The dome shape FP is surrounded by a pair of hairy bracts $(\mathrm{Br})$. Scale bar $=100 \mu \mathrm{m}$. (C) Top view of a FP with a pair of lateral developed sepals (S). Scale bar $=20 \mu \mathrm{m}$. (D) Four S arch inwards. Scale bar $=$ $100 \mu \mathrm{m}$. (E) Three S were removed to show the initiation of the petals $(\mathrm{Pt})$. Scale bar $=50 \mu \mathrm{m}$. $(\mathbf{F})$ Cross section of a young flower bud showing the initiation of Pt and gynoecium $(\mathbf{G})$ under the S. Scale bar $=100 \mu \mathrm{m}$.

and gynoecium occurred under the sepals (Fig. 4E) during Stage II. The initiations of stamens occurred in a whorl between the petals and the gynoecium (Fig. 4F) during the late Stage II flower development period. Anthers and stylar canal developed (Fig. 5A) during early Stage III. Stigma formation occurred during Stage III while the petaloid staminodes developed at the same whorl with the anthers (Fig. 5B). During the style elongation, the petaloid staminodes developed toward the style and filled the space between the style and anthers (Fig. 5C). At early Stage IV, the stigma was at the same height with the petaloid staminodes, anthers, and petals (Fig. 5D). The style elongated and the stigma protruded above the anthers and petals when the flower was near anthesis.

The bisexual, solitary, small, and axillary types of flowers which were observed in this study are common flower characteristic for the Sapotaceae family (Achigan-Dako et al., 2015; Ayensu, 1972). The fusion of sepals was a unique characteristic of the genus Synsepalum when it was treated by Baillon (1891) as a new genera rather than that section proposed by Candolle (1844). The calyx had a protective function for the developing flower in which the trichomes on the calyx and the fusion of calyx made protection against herbivore more efficient (Ingrouille, 2007a). The fusion of sepals, corolla, petaloid staminodes, and stamens prevents the flower of miracle fruit to open completely. Ayensu (1972) reported the differences between petals and petaloid staminodes in fresh samples of miracle fruit. However, the function of the petaloid staminodes is unknown.

Walker-Larsen and Harder (2000) reported that most of the petaloid staminodes in Asteridae had no recognized function and 
they considered such nonfunctional staminodes will be lost quickly. However, such structures may have a function in the flower, which has not been discovered to date (Decraene and Smets, 2001). In hermaphordite flower, the petal-like structure or petaloid stamen was an expansion of the filament and functions as a barricade between the anther and stigma, which may avoid pollen transfer to the stigma. Dense tapering trichomes were observed covering the ovary at a very early stage where the trichomes were thought to protect the young ovary against pests.

Doming on the apical meristem is the first morphological indication of the transition to flowering (Foster et al., 2003). Further flower development occurred on the dome apical meristem with beginning sepals, petals, stamens, gynoecium, and petaloid staminodes. Miracle fruit possesses evidence of antesepalous staminodes. The antesepalous staminodes will be visible only after the initiation of the common stamen-petal primordial (Decraene and Smets, 2001) and carpels. This phenomenon is almost the same as Paronychia decandra, Samolus valerandi, and Magodendron (Decraene and Smets, 1995; Vink, 1995). According to Chase et al. (1993), the Sapotaceae was grouped under the order Asteridae where animal pollination predominates. Miracle fruit exhibits the tubular flowers, however, in conditions with less wind pollination it favors animal pollinated flower type (WalkerLarsen and Harder, 2000). The fused floral parts of miracle fruit places each part in a precise position relative to the others as part of an architecture designed to encourage particular kinds of pollinator behavior (Ingrouille, 2007b). The partially opened flower anthesis in the evening along with strong scent are evidences that this flower is attracting certain animals or insects as pollinators. The orientation of the flower to droop down provides gravitational pull for anther to drop toward the petal apex and opening during anthesis. From the observations in this study, the rest of the floral structure including the pistil wilted later than the stamen, therefore the chances of pollen to pollinate the receptive stigma was very low. Pollen accumulation at the tip of the petal may also assist pollinators as they do not have to reach the shorter stamens. The different time in stamen wilting compared with the stigma, being stigma position above the anther, and the presence of petaloid stamen strongly suggested that this species is toward animal-pollinated flower type and prevention of self-pollinations. In some other economically important fruit species such as Anacardium occidentale L., Musa spp., and Mangifera indica L., pollinators play a crucial role in yield which can be increased by $60 \%$ to $157 \%$ (Abrol, 2012). However, for S. dulcificum, it is not clear what pollinators and in which proportion they contribute to increase yield potential and fruit quality. Answers to these questions are prerequisite to successful breeding programs.

Fruit development of miracle fruit. A miracle fruit branch was able to produce about 20 to 50 flowers with 1 to 5 flowers
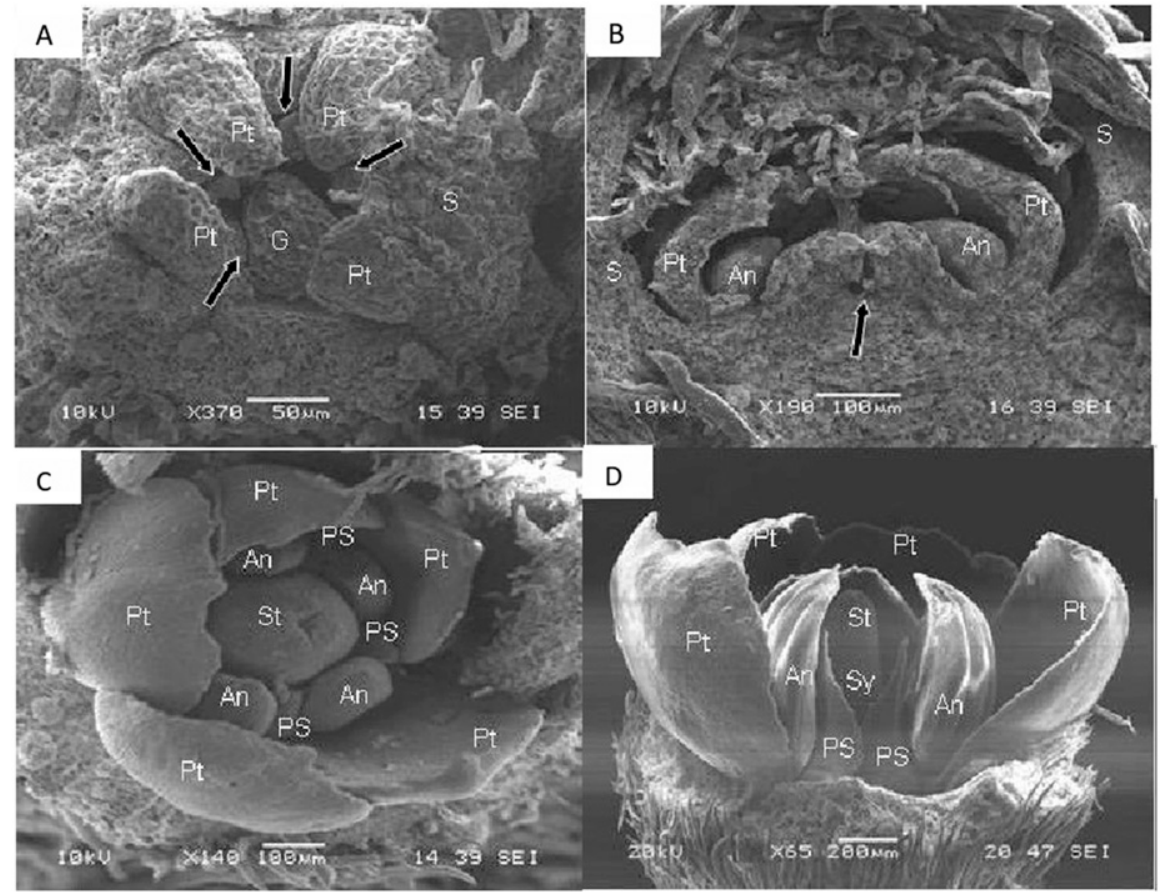

Fig. 5. Micrograph showing flower development of Synsepalum dulcificum. (A) The stamens (arrowed) initiated in the whorl between the petals $(\mathrm{Pt})$ and the gynoecium $(\mathrm{G})$. Scale bar $=50 \mu \mathrm{m}$. (B) Cross section of a developing flower bud showing anthers (An) and stylar canal (arrowed) develop under the petals (Pt) and sepals (S). Scale bar $=100 \mu \mathrm{m}$. (C) Top view of a flower bud at Stage III, showing the formation of stigma (St), while the petaloid staminodes (PS) developed at the same whorl with the An. Scale bar $=100 \mu \mathrm{m}$. (D) Side view of a flower bud at the late stage III flower development, one Pt and An were removed to show further development and enlargement of An and elongation of the style (Sy) and the PS filled the space between the Sy and An. Scale bar $=200 \mu \mathrm{m}$.

exhibiting anthesis at a time. The petals turned brown and wilted $2 \mathrm{~d}$ after anthesis while the style remained fresh for 1 week. However, the stigma was no longer receptive where it appeared dried. The style was dried up and turned black within $25 \mathrm{~d}$ after anthesis but remained persistently attached to the ovary throughout the fruit developing process (Fig. 6). The ovary was not visible for the first 5 weeks of fruit development and the ovary was protected by the hairy calyx. The enlargement of the ovary within the calyx was noticeable $30 \mathrm{~d}$ after anthesis. The ovary was visible $40 \mathrm{~d}$ after anthesis and it continued to enlarge and elongate for the next $35 \mathrm{~d}$. The width of the ovary increased from 2 to $8 \mathrm{~mm}$ and the length increased from 3 to $15 \mathrm{~mm}$. Heavy premature fruit dropping ranging from $79.2 \%$ to $100 \%$ occurred during 40 $60 \mathrm{~d}$ after anthesis when the young fruits were between $2 \mathrm{~mm}$ in width and 3 to $6 \mathrm{~mm}$ in length. In this study, the average of recorded final fruit set was $5.06 \%$ per plant. The fruit developed fully at $85 \mathrm{~d}$ after anthesis and ripened within $5 \mathrm{~d}$ with the color change from green to red during the ripening process. Flowers that developed at the leaf axils near to the apex of a branch had higher chances to set fruits (Fig. 7) compared with the flowers that developed near to the basal part of a branch.

Many factors may determine fruit set and premature fruit drop; including the weather, late blooming, pollinator activity, self-incompatibility, tree health and nutrition,

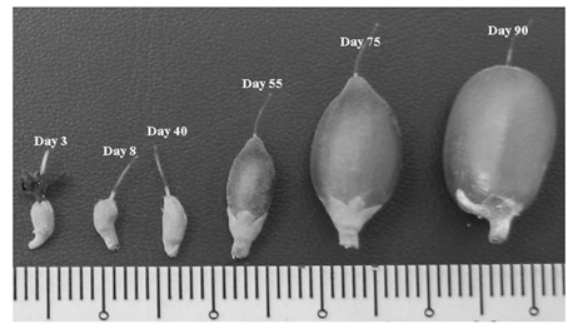

Fig. 6. Fruit development of Synsepalum dulcificum. Petals wilted and turned brown, stigma dried while the style remains fresh (2-7 d after anthesis); style dried and turned black but persistently attached to the developing ovary which is protected by the hairy calyx $(8-39 \mathrm{~d}$ after anthesis); the ovary become visible and continues to enlarge and elongate (40-74 d after anthesis); fully developed green fruit (75$85 \mathrm{~d}$ after anthesis); fruit ripened and turned red (85-90 d after anthesis). Scale bar $=1 \mathrm{~mm}$.

and light penetration into the tree canopy (Evans et al., 2010; Honsho et al., 2004). Higher fruit set on flowers near the stem apex may be related to greater light and greater accessibility to pollinators (Evans et al., 2010). The number of flowers per plant was excessive in miracle fruit, which may contribute to the large number of premature fruit drop was observed at the early stage of fruit development. Competition for carbohydrates and hormones among young fruits could also be one of the reasons for high percentage of fruit drop (Ryugo, 1988). 

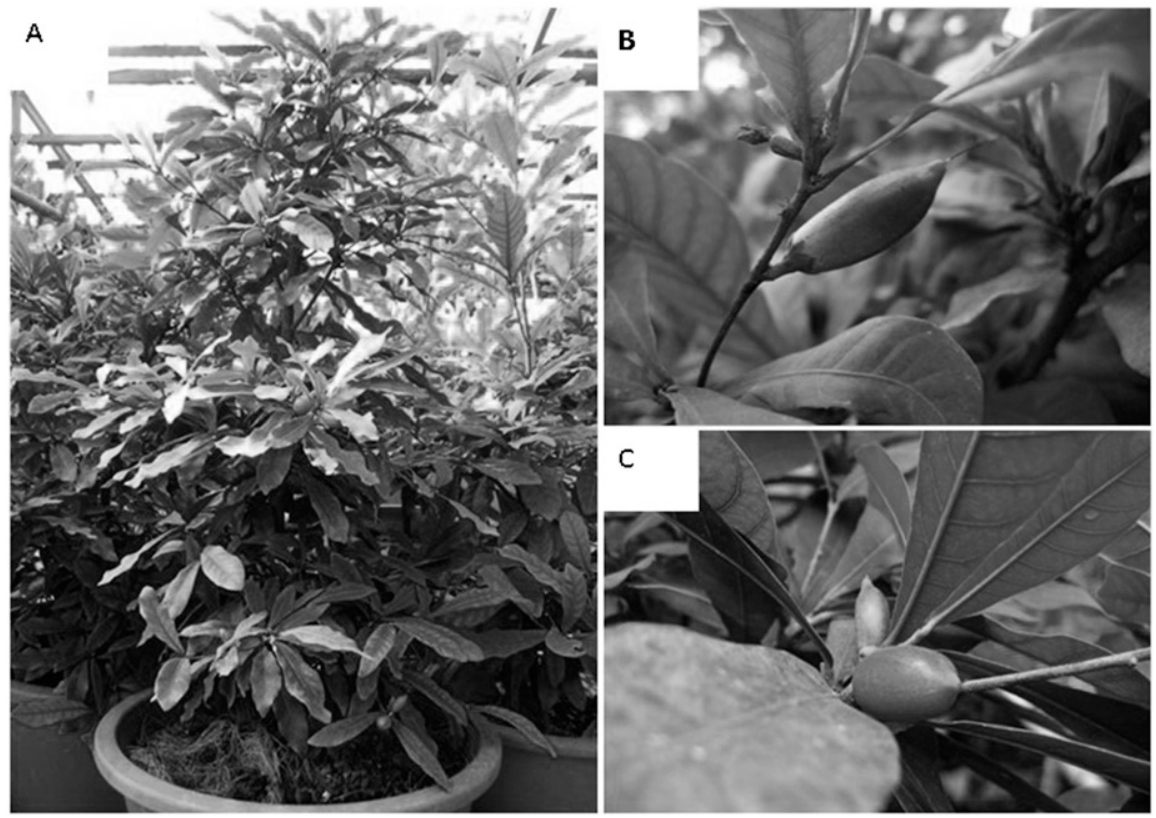

Fig. 7. Fruiting position of Synsepalum dulcificum. (A) A 4-year-old fruiting plant with red ripened fruits bearing at the shoot apex of each branch. (B) Close up of a fruiting branch with a ripening fruit and a senescent flower. (C) A ripened fruit and a green fruit at the leaf axils near the shoot apex.

The early fruit drop in miracle fruit could also be due to competition between the young fruit and vegetative growth during the period which is critical to fruit retention and yield (40-60 d after anthesis). Water stress during the early fruit developmental stage could induce the production of stressinduced hormones or growth inhibitors such as abscisic acid leading early fruit dropping. Successful pollination coupled with proper nutrient and water management could decrease premature fruit drop and obtain greater miracle fruit yield.

The role of insect pollinators may have been previously underestimated as factors influencing fruit set in miracle fruit. Since the plant tends to prevent self-pollination and minimizes flower synchrony, a higher density of tree planting could aid in increasing pollen source and facilitate successful crosspollination.

\section{Conclusion}

Synsepalum dulcificum has many benefits for local populations and a great potential in food and drug industries. Since the past 20 years, extensive research on miraculin has been carried out but aspects on plant propagation, establishment, and reproductive biology have not been given much attention. Propagation using cuttings should be investigated for early fruiting plant materials. Studies on reproductive biology, pollination ecology, fruit set, and development are important to understand the flowering and fruiting behavior of miracle fruit. Observations in this study indicated that a miracle fruit flower took $100 \mathrm{~d}$ to develop from reproductive meristem to full anthesis and the flower development can be divided into six stages where both male and female reproductive organs were found developing during stage III from 66 to $85 \mathrm{~d}$. The petaloid staminodes which served an unknown function initiated lastly at the same whorl with the common stamens. Heavy fruit dropping was observed at 40-60 d after anthesis which contributed to low fruiting percentage. The fruit with persistent style developed and ripened $90 \mathrm{~d}$ after anthesis. From the observations on the flowering behavior and flower architecture in this study, miracle fruit is suggested to be insect pollinated and has features that prevent self-fertilization. A study on pollination ecology needs to be carried out to identify the pollinator for miracle fruit as this is important in manipulating fruit loading in the future. Besides that, cropping system and plant nutrition programs need to be devised for optimizing the yield. Plant density, amount of fertilizer, and time of fertilizer application are important in successfully managing the fruit crop.

\section{Literature Cited}

Abrol, D.P. 2012. Pollination-basic concepts, p. 37-54. In: D.P. Abrol (ed.). Pollination biology. Springer, Berlin, Germany.

Achigan-Dako, E.G., D.A. Tchokponhoué, S. N'Danikou, J. Gebauer, and R.S. Vodouhè. 2015. Current knowledge and breeding perspectives for the miracle plant Synsepalum dulcificum (Schum. et Thonn.). Daniell. Genet. Resour. Crop Ev. 62:465476.

Albrechtova, J.T.P., M. Dueggelin, M. Duerrenberger, and E. Wagner. 2004. Changes in the geometry of the apical meristem and concomitant changes in cell wall properties during photoperiodic induction of flowering in Chenopodium rubrum. New Phytol. 163:263-269.

Ayensu, E.S. 1972. Morphology and anatomy of Synsepalum dulcificum (Sapotaceae). Bot. J. Linn. Soc. 65:179-187.

Baillon, H.E. 1891. Synsepalum dulcificum. Hist. Plantarum. 11:286.

Candolle, A.D. 1844. Sideroxylon dulcificum. Prodromus Syst. Nat. Veg. 8:183.

Chase, M.W., D.E. Soltis, R.G. Olmstead, D. Morgan, D.H. Les, B.D. Mishler, and K.A. Kron. 1993. Phylogenetics of seed plants: An analysis of nucleotide sequences from the plastid gene rbcL. Ann. Mo. Bot. Gard. 80:528-580.

Chen, X.W., T.L. Abdullah, N.A.P. Abdullah, and S.A. Hassan. 2012. Rooting response of miracle fruit (Synsepalum dulcificum) softwood cuttings as affected by indole butyric acid. Amer. J. Agr. Biol. Sci. 7:442-446.

Decraene, L.P.R. and E.F. Smets. 1995. The distribution and systematic relevance of the androecial character oligomery. Bot. J. Linn. Soc. 118:193-247.

Decraene, L.P.R. and E.F. Smets. 2001. Staminodes: Their morphological and evolutionary significance. Bot. Rev. 67:351-402.

Dennis, E.S., C.A. Helliwell, and W.J. Peacock 2006. Vernalization: Spring into flowering. Dev. Cell 11:1-7.

Du, L., S. Yixiao, Z. Xiumei, P. Witoon, and X. Zhimin. 2014. Antioxidant-rich phytochemicals in miracle berry (Synsepalum dulcificum) and antioxidant activity of its extracts. Food Chem. 153:279-284.

Esumi, T., R. Tao, and K. Yonemori. 2007. Comparison of early inflorescence development between Japanese pear (Pyrus pyrifolia Nakai) and quince (Cydonia oblonga Mill.). J. Jpn. Soc. Hort. Sci. 73:210-216.

Evans, L.J., R.M. Goodwin, and H.M. McBrydie. 2010. Factors affecting 'Hass' avocado (Persea americana) fruit set in New Zealand. New Zealand Plant Protection. 63:214-218.

Foster, T., R. Johnston, and A. Seleznyova. 2003. A morphological and quantitative characterization of early floral development in apple (Malus x domestica Borkh.). Ann. Bot. 92:199-206.

Honsho, C., K. Yonemori, S. Somsri, S. Subhadrabandhu, and A. Sugiura. 2004. Marked improvement of fruit set in Thai durian by artificial cross-pollination. Sci. Hort. 101:399-406.

Ingrouille, M. 2007a. Sepals, p. 110-111. In: K. Roberts (ed.). Handbook of plant science. Wiley, England.

Ingrouille, M. 2007b. Flowers, p. 104-110. In: K. Roberts (ed.). Handbook of plant science. Wiley, England.

Jaeger, K.E., A. Graf, and P.A. Wigge. 2006. The control of flowering in time and space. J. Expt. Bot. 57:3415-3418.

Kant, R. 2005. Sweet proteins: Potential replacement for artificial low calorie sweeteners. Nutr. J. 4:1.

Kassel, R.G. and C.Y. Shih. 2012. Scanning electron microscopy in biology: A students' atlas on biological organization. Springer Science \& Business Media.

Kurokura, T., Y. Inaba, D. Neri, and N. Sugiyama. 2005. A morphological study of the development of the second inflorescences in strawberry (Fagaria $\mathrm{x}$ ananassa Dush.). Ann. Appl. Biol. 146:511-515.

Kwiatkowska, D. 2006. Flower primordium formation at the Arabidopsis shoot apex: Quantitative analysis of surface geometry and growth. J. Expt. Bot. 57:571-580.

Oumorou, M., J. Dah-Dovonon, B.A. Aboh, M. Hounsoukaka, and B. Sinsin. 2010. Contribution a' la conservation de synsepalum dulcificum: 
Re'ge'ne'ration et importance socioe'conomique dans le de'partement de l'oue'me' (Be'nin). Ann. Sci. Agron. 14:101-120.

Ryugo, K. 1988. Fruit culture. Its science and art. Wiley, New York, NY.

Teeri, T.H., A. Uimari, M. Kotilainen, R. Laitinen, H. Help, P. Elomaa, and V.A. Albert. 2006. Reproductive meristem fates in Gerbera. J. Expt. Bot. 57:3445-3455.
Temussi, P.A. 2006. Natural sweet macromolecules: How sweet proteins work. Cell. Mol. Life Sci. 63:1876-1888.

Tromp, J. 2000. Flower-bud formation in pome fruits as affected by fruit thinning. Plant Growth Regulat. 31:27-34.

Valiente, J.I. and L.G. Albrigo. 2004. Flower bud induction of sweet orange trees (Citrus sinensis Osbeck): Effect of low temperatures, crop load and bud age. J. Amer. Soc. Hort. Sci. 129:158164.

Vink, W. 1995. Revision of Magodendron (Sapotaceae) with observations on floral development and morphology. Blumea 40:91-107.

Walker-Larsen, J. and L.D. Harder. 2000. The evolution of staminodes in Angiosperms: Patterns of stamen reduction, loss, and functional re-invention. Amer. J. Bot. 87:1367-1384. 